\title{
O Pesadelo de um Milhão de CoIsAs - \\ A escrita da alucinação em Flaubert e Perec
}

por Carolina Augusto Messias ${ }^{1}$

\section{RESUMO}

Partindo da discussão da descrição flaubertiana em L'Éducation sentimentale, este artigo visa apresentar a análise de alguns procedimentos literários que compõem uma escrita da alucinação nesse romance e a forma como Georges Perec retrabalha essa questão em seu Les choses. Com isso, pretende-se ilustrar o importante papel que os objetos têm nos dois romances, adquirindo um "valor-ação" em Flaubert, devido ao trabalho com verbos de ação ligados aos objetos e sendo personagens de uma "descrição narrativa" em Perec, em sua re-escritura que questiona os limites entre o descritivo e o narrativo.

PALAVRAS-CHAVE: Gustave Flaubert, Georges Perec, descrição, alucinação.

\section{RÉSUMÉ}

À partir de la discussion à propos de la description flaubertienne dans L'Éducation sentimentale, cet article envisage de présenter l'analyse de quelques procédures littéraires qui composent une écriture de I'hallucination dans ce roman et la forme dont Georges Perec s'approprie de cette question dans son roman Les choses. On a l'intention d'illustrer le rôle joué par les objets dans ces deux romans: la "valeur-action " des objets chez Flaubert, à partir du travail avec les verbes d'action liés aux objets et la "description narrative " chez Perec, où les objets jouent le rôle des personnages et dont la réécriture de Les choses questionne les limites entre le descriptif et le narratif.

MOTS-CLÉS: Gustave Flaubert, Georges Perec, description, hallucination.

Neste artigo, pretendemos analisar de que forma a descrição empreendida por Flaubert constrói uma escrita da alucinação no romance L'Éducation sentimentale (1869), e como Georges Perec, em seu primeiro romance Les choses (1965), retoma essa questão de forma inovadora. Nenhum dos dois romances pretende apresentar um simples relato ficcional das gerações em que estavam inseridos, Flaubert e Perec buscam construir imagens por meio da subversão ou da potencialização de alguns procedimentos literários, os quais gostaríamos de discutir neste artigo.

Adotamos o termo alucinação ligado à escrita baseados na tese de Verónica Galindez Jorge (2003), que compreende a alucinação como mecanismo da produção imagética flaubertiana, por esse motivo, não nos preocuparemos em abordar as outras acepções desse termo, pois entendemos que:

Sem a preocupação estritamente conceitual, podemos ler na alucinação, como já anunciamos, a saturação de imagens, a confusão de tempos. Assim, passaremos a questionar a própria função descritiva, a partir de sua construção. (JORGE, 2003, p. 172)

\footnotetext{
${ }^{1}$ Mestranda na Área de Língua e Literatura Francesa FFLCH/USP e membro do grupo Criação e Crítica. E-mail: carolina.messias@usp.br
} 
Nos romances de Flaubert e de Perec, há uma profusão de coisas que podem causar certo tédio ou estranhamento na leitura devido à sua relação com os personagens e com a nossa própria visão de mundo. Através da enumeração de objetos e de características, até mesmo de forma ilógica, e do emprego de tempos verbais incomuns para uma descrição, Flaubert questionará a relação causal ou afetiva com que os objetos apareciam nos romances românticos e realistas. Sua forma de escrever revela uma nova descrição dos objetos, os quais não estão mais em função de um personagem, mas podem existir por meio dele, do seu olhar. A descrição flaubertiana não pretende ser explicativa, no sentido de que não pretende construir um objeto ou mostrar sua função no romance, por exemplo, caracterizar uma personagem pela roupa que usa ou explicar minuciosamente o funcionamento de uma máquina que aparece no romance, como acontecia nos romances de Balzac. Contudo, a forma como a descrição é construída por Flaubert cria a sensação de uma não-gratuidade. Por esse motivo, decidimos não pular as páginas para ver o que vai acontecer no próximo capítulo, mas investigá-las e questioná-las, isto é, discutir a composição dessa descrição.

A primeira parte deste artigo tratará dessa nossa inquietação com a descrição flaubertiana em alguns trechos de L'Éducation.... Na segunda, discutiremos como Perec retrabalhou a mesma questão em Les choses de forma que a alucinação ganhe espaço numa espécie de "descrição-narrativa".

\section{Em torno de Flaubert : uma escrita que perturba}

Por volta de 1850, começa-se a criar o mito do escritor-artesão, aquele que trabalha a linguagem como um artesão trabalha o material bruto. Como fundador de uma escrita artesanal, Flaubert cria várias metáforas para falar de seu processo escritural, como um "mecanismo estranho" e uma longa viagem que the faz sentir mal. Por outro lado, essas metáforas não poderiam ser empregadas aos leitores de Flaubert? A leitura dos romances e dos contos flaubertianos é também uma viagem na qual devemos portar alguns instrumentos para compreender esse "mecanismo" e sair do estranhamento gerado pelo estilo do autor.

Por meio do trabalho com as descrições, com os tempos verbais e o com foco narrativo, Flaubert questiona tanto a tradição romântica, baseada na idéia de criação pela inspiração de um gênio, quanto a proposta realista que vinha sendo desenvolvida no XIX, fortemente influenciada pela ciência baseada na experimentação e na observação com o advento das idéias de Lamarck e Darwin ${ }^{2}$. Enquanto o cientificismo entrava na literatura, por exemplo, para explicar a conduta de determinado personagem por ter características semelhantes a de um animal irracional, Flaubert se colocava contra o romance ilustrado e incluía esses discursos científicos, trabalhando-os sob um novo olhar, sem partir de uma observação imparcial e objetiva, mas de uma observação subjetiva, que poderíamos chamar "subjetivismo".

\footnotetext{
${ }^{2}$ Segundo Jorge (2003), "Flaubert transita entre uma tradição romântica, caracterizada pela inspiração, pela criação ex-nihilo, e uma arte realista-naturalista em configuração, esta fortemente influenciada pela ciência do séc. XIX, caracterizada essencialmente pela observação".
} 
Segundo Proust, esse subjetivismo em Flaubert é caracterizado por um estado que se prolonga por meio de verbos no pretérito imperfeito, ou em que os tempos são misturados e as coisas adquirem tanta vida quanto os personagens:

O subjetivismo de Flaubert exprime-se por um novo emprego dos tempos dos verbos, das preposições, dos advérbios, os dois últimos tendo quase nunca em sua frase senão um valor rítmico. Um estado que se prolonga é indicado pelo imperfeito. Toda essa segunda página da Educação (página tomada absolutamente por acaso) compõe-se de imperfeitos, exceto quando intervém uma mudança, uma ação, ação cujos personagens são geralmente coisas ("a colina perdeu altura" etc.). (PROUST, 1920)

Proust destaca uma característica importante da escritura flaubertiana: o distanciamento de uma descrição objetiva e a atribuição de um valor-ação às coisas. Não estamos tratando aqui do simples binômio "coisificação dos personagens" e "personificação das coisas", mas da importância que esse valor-ação das coisas tem na construção de uma escrita da alucinação.

Examinemos, por exemplo, o trecho ${ }^{4}$ a seguir de L'Éducation..., em que Frédéric sai da realidade e sonha ser um escritor ou um pintor. Os discursos do narrador onisciente e do personagem se confundem quando o relógio de uma igreja bate uma hora e Frédéric chega a ter uma espécie de revelação superior, de epifania:

II s'était arrêté au milieu du Pont-Neuf, et, tête nue, poitrine ouverte, il aspirait l'air. Cependant, il sentait monter du fond de lui-même quelque chose d'intarisable, un afflux de tendresse qui l'énervait, comme le mouvement des ondes sous ses yeux. À I'horloge d'une église, une heure sonna, lentement, pareille à une voix qui l'eût appelé.

Alors, il fut saisi par un de ces frissons de l'âme où il vous semble qu'on est transporté dans un monde supérieur. Une faculté extraordinaire, dont il ne savait pas l'objet, lui était venue. II se demanda, sérieusement, s'il serait un grand peintre ou un grand poète; - et il se décida pour la peinture, car les exigences de ce métier le rapprocheraient de Mme Arnoux. II avait donc trouvé sa vocation! Le but de son existence était clair maintenant, et l'avenir infaillible.

\footnotetext{
3 « Le subjectivisme de Flaubert s'exprime par un emploi nouveau des temps des verbes, des prépositions, des adverbes, les deux derniers n'ayant presque jamais dans sa phrase qu'une valeur rythmique. Un état qui se prolonge est indiqué par l'imparfait. Tout cette deuxième page de L'Éducation (page prise absolument au hasard) est faite d'imparfaits, sauf quand intervient un changement, une action, une action dont les protagonistes sont généralmente des choses ("la colline s'abaissa », etc). PROUST, M. " A propos du 'style' de Flaubert » Tradução retirada de PROUST, M. Nos caminhos da crítica. São Paulo: Imaginário, 1994, p. 71.

${ }^{4}$ O leitor encontrará, em nota de rodapé, a tradução para o português dos trechos dos romances citados neste artigo apenas para fins ilustrativos. As traduções não serão contempladas na análise.
} 
Quand il eut renfermé sa porte, il entendit quelqu'un qui ronflait, dans le cabinet noir, près de la chambre. C'était l'autre. II n'y pensait plus. ${ }^{5}$ (FLAUBERT, G. (1869), 1998, p. 75-6, grifo nosso)

Frédéric está no meio do Pont-Neuf e o movimento das ondas que ele observa produz quelque chose d'intarisable em sua alma. Em seguida, o som do relógio de uma igreja Ihe faz lembrar uma voz e, então, acontece uma revelação: seu futuro como pintor (um futuro que não acontece, como nós saberemos ao longo do livro). As relações temporais aqui são extremamente individuais, a memória está ligada à subjetividade e ao inconsciente do personagem. A associação livre entre quelque chose d'intarisable (algo inesgotável) e le mouvement des ondes (o movimento das ondas), e entre o som de l'horloge d'une église (relógio de uma igreja) e une voix qui l'eût appelé (uma voz que o teria chamado), é um recurso muito utilizado nas práticas terapêuticas psicanalíticas, com Charcot e, mais tarde Freud no tratamento da histeria, cujo objetivo era fazer a paciente falar sem ser interrompida, permitindo que ela narrasse sua história livremente produzindo, assim, imagens que não se relacionavam de forma direta e clara. No trecho apresentado, temos a incorporação desse tipo discurso que circulava no final do século XIX que visa produzir imagens sem uma relação de causa e efeito. Além disso, observamos que alucinação será desencadeada por um objeto, no caso, o relógio da igreja, que será associado a uma voz e a partir dessa imagem, o narrador constrói a imagem da revelação de Frédéric.

Destacamos, também, no trecho apresentado, uma frase em que o narrador emprega, curiosamente, os pronomes vous e on: "Alors, il fut saisi par un de ces frissons de l'âme où il vous semble qu'on est transporté dans un monde supérieur.". O narrador conta o evento no passado, mas inclui o leitor, empregando o verbo no presente do indicativo! Ele partilha, portanto, a sensação dos arrepios na alma de Frédéric com o leitor, ou melhor, ele dá ao leitor a função de julgar o que seria um arrepio na alma que nos transporta para um mundo superior, sem nada explicar de antemão. O narrador nos conta, em seguida, que Frédéric decide se ele seria um grande poeta ou um grande pintor e, depois de um vazio pontuado por uma pausa - marcada por ponto e vírgula e travessão -, ele nos narra apenas a escolha do personagem pela pintura por causa de Mme Arnoux.

Além disso, o narrador onisciente partilha da alucinação do personagem quando ele exclama a descoberta de Frédéric e declara seu futuro infalível ("Il avait donc trouvé sa vocation! Le but de son existence était clair maintenant, et l'avenir infaillible.»). No entanto, a observação irônica do narrador nega o futuro brilhante de Frédéric, compondo a imagem de um personagem tolo ao acreditar nesse tipo de sensação de plenitude.

\footnotetext{
5 « Tinha chegado ao meio da Ponte-Nova [Pont-Neuf], e tirando o chapéu, de casaco desabotoado, aspirava o ar. Sentia, contudo, subir do fundo de si próprio um afluxo de ternura que o enervava, como o movimento das ondas, embaixo. No relógio de uma igreja, bateu uma hora, lentamente, semelhante a uma voz que chamasse por ele. Foi então tomado de um desses arrepios da alma em que nos sentimos transportados a um mundo superior. Uma faculdade extraordinária, cujo objetivo lhe escapava, surgira-lhe de repente. Pôs-se a perguntar a si mesmo, cheio de seriedade, se seria um grande pintor ou um grande poeta; - e decidiu-se pela pintura, porque as exigências desse mister aproximavam-no de Mme Arnoux. Tinha, pois, achado a vocação! O fim da sua existência era agora claro, e o futuro infalível.
}

Quando fechou a porta, ouviu alguém ressonar no gabinete escuro, junto do quarto. Era o amigo. Já nem pensava nele." FLAUBERT, Gustave (1869). A educação sentimental. Tradução revista e adaptada pelo corpo editorial. São Paulo: W. M. Jackson Inc., Coleção Romances Universais, vol.18, 1963, p.52-3. 
O final dessa passagem nos mostra a interrupção da ilusão através de uma cena irônica dos roncos do colega de quarto de Frédéric. Segundo Genette, há um acorde dissonante que se impõe nessas suas percepções (o sonho irreal versus a vida prosaica) que vibram da mesma forma, no mesmo espaço. (GENETTE, G. 1966, p.227)

Sobre essa espécie de sonho acordado, nós poderíamos estabelecer também uma relação entre as personagens flaubertianas Frédéric Moreau e Emma Bovary. De um lado, ele deseja ser escritor, pintor ou compor sonatas, de outro, ela aspira ser uma personagem de romances românticos. Os dois são, portanto, sonhadores. Por mais que Genette defenda que Frédéric não é bovarista, por não ter a mesma capacidade ilusória de Emma, é difícil caracterizá-lo como alguém lúcido. Observemos o trecho seguinte, que já foi analisado por Genette no ensaio «Silences de Flaubert»:

Quand il allait aux Jardin des Plantes, la vue d'un palmier l'entraînait vers des pays lointains. Ils voyageaient ensemble, au dos des dromedaires, sous le tendelet des éléphants, dans la cabine d'un yacht parmi des archipels bleus, ou côte à côte sur deux mulets à clochettes, qui trébuchent dans les herbes contre des colonnes brisées. Quelquefois, il s'arrêtait au Louvre devant de vieux tableaux; et son amour l'embrassant jusque dans les siècles disparus, il la substituait aux personnages des peintures. Coiffée d'un hennin, elle priait à deux genoux derrière un vitrage de plomb. Seigneuresse des Castilles ou des Flandres, elle se tenait assise, avec une fraise empesée et un corps de baleines à gros bouillons. Puis elle descendait quelque grand escalier de porphyre, au milieu des sénateurs, sous un dais de plumes d'autruche, dans une robe de brocart. D'autres fois, il la rêvait en pantalon de soie jaune, sur les coussins d'un harem; - et tout ce qui était beau, le scintillement des étoiles, certains airs de musique, l'allure $d$ 'une phrase, un contour, l'amenaient sa pensée d'une façon brusque et insensible ${ }^{6}$. (FLAUBERT, G. idem, p. 97, grifo nosso)

Genette analisa essa passagem como a descrição de um quadro em que a profusão de detalhes e a presença material, que caracterizam o estilo flaubertiano, são marcadas por uma subjetividade que faz referência a evocações vagas. De fato, o que é narrado nesse trecho é um pouco mais difuso e dinâmico do que uma pintura, ele nos lembra mais uma imagem cinematográfica, como Genette propôs no mesmo artigo, ou ainda, assemelha-se a uma alucinação acordada.

Mais uma vez, temos um valor-ação delegado às coisas, o Jardin des Plantes e as pinturas do Louvre iniciarão o processo alucinatório de Frédéric. $O$ narrador emprega o mesmo tempo verbal e não nos apresenta nenhuma indicação gráfica da mudança do foco

\footnotetext{
${ }^{6}$ « Quando ia ao Jardim Botânico, à vista de uma palmeira sentia-se arrastado para países longínquos. Viajavam juntos, no dorso dos dromedários, sob a tenda dos elefantes, no camarote de um iate entre arquipélagos azuis, ou lado a lado, em duas mulas de campainhas, que tropeçavam na erva, entre colunas truncadas. Às vezes parava no Louvre diante dos quadros antigos; e como o seu amor até cingia os séculos idos, substituía-a aos personagens das pinturas. De pontiaguda coifa medieval, via-a orar de joelhos por detrás de uma vidraça colorida. Senhora das Castelas ou das Flandres, conservava-se sentada, de gargantilha engomada e colete de baleia. Depois descia escadarias de pórfiro, no meio dos senadores, sob um pálio de plumas de avestruz, toda vestida de brocado. Outras vezes sonhava-a de calção de seda amarela, nos coxins de um harém; e tudo o que era belo, o cintilar das estrelas, certos trechos de uma música, o recorte de uma frase, um contorno, traziamIha ao pensamento de modo busco e insensível." (FLAUBERT, G. idem, p.71-2)
} 
narrativo. Sem nenhuma implicação lógica, a vista de uma palmeira no Jardin des Plantes o remete a imagens de países longínquos e as imagens seguintes serão descritas cumulativamente. A frase cria um palimpsesto, isto é, tudo acontece ao mesmo tempo e não é possível dar uma sequência temporal ou lógica aos fatos.

Genette apresenta uma relação muito interessante entre a escrita flaubertiana e o cinema, que também será pertinente para falar da escritura perecquiana mais tarde, além de tocar num dos traços mais característicos do estilo de Flaubert:

O estilo de Flaubert parece frequentemente tão refratário à interiorização quanto à imagem cinematográfica. Talvez, pois o cinema tem, para ele, apenas a imagem visual e o som, mas a escritura flaubertiana joga, através da tela da representação verbal, sobre todos os modos sensíveis (tátil, em particular) da presença material. (GENETTE, 1966, p.228)

Esse jogo através de todos os modos sensíveis produz um efeito no leitor, já que não há, na obra de Flaubert, uma busca pela plenitude referencial própria da tradição realista. Como vimos na cena do Jardin des Plantes, a passagem da "realidade" ao sonho não é indicada pelo narrador, o leitor deve se guiar sozinho na alucinação de Frédéric. Quando o personagem ia ao Louvre e parava diante dos velhos quadros, os personagens das pinturas o remetiam à figura de Mme Arnoux. Em seguida, o discurso do narrador onisciente se mistura à imaginação de Frédéric, pois Mme Arnoux é descrita como se ela fizesse o papel das personagens femininas dos três quadros apresentados: "Coiffée d'un hennin, elle priait à deux genoux derrière un vitrage de plomb. Seigneuresse des Castilles ou des Flandres, elle se tenait assise, avec une fraise empesée et un corps de baleines à gros bouillons. Puis elle descendait quelque grand escalier de porphyre, au milieu des sénateurs, sous un dais de plumes d'autruche, dans une robe de brocart ".

É preciso destacar também o emprego do imperfeito, que coloca a ilusão na mesma diegése, no mesmo universo espaço-temporal designado pela narração. Segundo Proust, «(...) esse imperfeito eterno, em parte composto pelas palavras dos personagens os quais Flaubert habitualmente coloca em estilo indireto para que elas se confundam com o restante (...) » (PROUST, 1920) ${ }^{8}$, e notamos isso sistematicamente nos excertos analisados anteriormente. O emprego de um tempo verbal que perpetua as ações corrobora as imagens criadas nessa alucinação. A indicação gráfica do ponto e vírgula seguido pelo travessão coloca uma pausa na alucinação e sublinha um resumo de tudo o que provocou em Frédéric o frisson por Mme Arnoux : "; - et tout ce qui était beau, le scintillement des étoiles, certains airs de musique, l'allure d'une phrase, un contour, l'amenaient sa pensée d'une façon brusque et insensible. ". Observamos, enfim, que a percepção de Frédéric é caracterizada pelas profissões, os papéis que ele gostaria de representar: músico de sonatas, escritor ou pintor.

\footnotetext{
${ }^{7}$ « Le style de Flaubert semble souvent aussi réfractaire à l'intéorisation que l'image cinématographique. Davantage, peut-être; car le cinéma n'a pour lui que l'image visuelle et le son, mais l'écriture flaubertienne joue, à travers l'écran de la représentation verbale, sur tous les modes sensibles (tactile, en particulier) de la présence matérielle.» (tradução livre).

8 «(..) cet éternel imparfait, composé en partie des paroles des personnages que Flaubert rapporte habituellement en style indirect pour qu'elles se confondent avec le reste (...) » (trad. 1971)
} 
Vejamos um último trecho de L'Éducation em que novamente um objeto, neste caso, uma carta, promoverá a alucinação de Frédéric, ilustrando, mais uma vez, o que defendemos aqui como valor-ação dos objetos. Após a alegria de se descobrir herdeiro da fortuna de um tio distante, Frédéric tem uma visão alucinante de Mme Arnoux como sua amante. Não é por acaso que os tempos verbais e os focos narrativos são, mais uma vez, embaralhados nesta cena:

II relut la lettre trois fois de suite; rien de plus vrai! Toute la fortune de l'oncle! Vingt-sept mille livre de rente! - et une joie frénétique le bouleversa, à l'idée de revoir Mme Arnoux. Avec la netteté d'une hallucination, il s'aperçut auprès d'elle, chez elle, lui apportant quelque cadeau dans du papier de soie, tandis qu'à la porte stationnerait son tilbury, non, un coupé plutôt!_un coupé noir, avec un domestique en livrée brune; il entendait piaffer son cheval et le bruit de la gourmette se confondant avec le murmure de leurs baisers. Cela se renouvellerait tous les jours, indéfiniment. II les recevrait chez lui, dans sa maison; la salle à manger serait en cuir rouge, le boudoir en soie jaune, des divans partout! Et quelles étagères! Quels vases de Chine! quels tapis! Ces images arrivaient si tumultueusement, qu'il sentait la tête lui tourner. Alors, il se rappela sa mère; et il descendit, tenant toujours la lettre à sa main ${ }^{9}$. (FLAUBERT, G., idem , p. 131, grifo nosso)

Utilizando o discurso (in)direto livre, o narrador mistura sua voz à de Frédéric que leu três vezes a mesma carta e parece gritar para comprovar a veracidade de seu conteúdo: «rien de plus vrai! Toute la fortune de l'oncle! Vingt-sept mille livre de rente!». Não só deixou claro que receberia toda a fortuna de seu tio (termo indefinido), como estipulou o valor herdado (termo definido). A pausa marcada pelo travessão, insere novamente a voz do narrador extradiegético que comentará a alegria frenética que aquele objeto (carta ou dinheiro) causará na alma de Frédéric, o que o levará à lembrança de Mme Arnoux.

O narrador extradiegético invade a memória do personagem e conta, de forma muito pertubadora, que Frédéric s'aperçut (notou-se) aos pés dela tandis qu'à la porte stationnerait son tilbury, non, un coupé plutôt! (enquanto na porta estacionaria seu tílburi, não, antes um cupê!). Há, portanto, uma mudança dos tempos verbais de uma ação pontual, narrada no passado (passé simple), tempo da narração, até a suspensão num futuro sonhado, provocado pelo emprego de um verbo no condicional (conditionnel), e, em seguida, há uma suspensão no tempo indicado pelo verbo 'entendre' (escutar) no imperfeito (imparfait).

A confusão entre os tempos empregados é reforçada pelo problema do ponto de vista. É a voz do Frédéric, em discurso indireto livre, que muda a antiga carroça movida a

\footnotetext{
9 "Releu a carta três vezes a seguir; era certo; toda a fortuna do tio! Vinte e sete mil francos de renda! - e sentia-se agitado por uma alegria frenética, com a idéia de tornar a ver Mme Arnoux. Com a nitidez de uma alucinação, via-se ao seu lado, em sua casa, levando-lhe presentes em papel de seda, enquanto à porta estacionava o tílburi, não, antes um cupê! Um cupê preto com um lacaio de libré escura; ouvia escarvar o cavalo e o ruído da baerbela misturar-se ao murmúrio dos seus beijos. E isso repertir-se-ia todos os dias, indefinidamente. Recebe-la-ia em casa dele; a sala de jantar seria de couro vermelho, o boudoir de seda amarela, divãs por toda parte! E que prateleiras! Que vasos da China! Que tapetes ! Estas imagens chegavamIhe tão tumultuosamente que sentia a cabeça à roda. Então lembrou-se da mãe; e desceu, sem largar a carta da mão." FLAUBERT, G. idem. p.102
} 
cavalo por um cupê preto. Entretanto a barbela (gourmette) permanece na cena e o cavalo continua a escavar para que os ruídos se confundam com o murmúrio dos beijos dos amantes na alucinação. Constatamos que não há uma linearidade, uma sequência lógica de imagens, ao contrário, uma palavra chama outra e mais outra num processo de associação livre, próprio do funcionamento do sonho. A descrição da sala de jantar ilustra bem esse procedimento e revela fazer parte do discurso do personagem e não do narrador, como comprovam as exclamações.

A descrição dos objetos da casa marca a acumulação material, la pensée meublée própria de Flaubert, que revela ironicamente essa ansiedade burguesa pelos objetos. Em sua alucinação, as coisas supérfluas poderiam ser exclamadas por Frédéric, orgulhoso de sua bela casa e da inveja dos demais personagens por sua riqueza. Quando Frédéric se lembra de sua mãe, essa suspensão no tempo cessa e ele retorna à realidade, como nos indica o verbo empregado pontualmente no pretérito perfeito ("lembrou-se da mãe").

Os excertos aqui apresentados revelam o desejo por Mme Arnoux a partir de todos os tipos de percepção do jovem Frédéric. Após a aparição de Mme Arnoux no barco Ville-deMontereau, tudo que era belo (o futuro como músico de sonatas, a visão de uma palmeira no Jardin de Plantes, as frases de uma carta) inspirará a imagem daquela senhora na alma de Frédéric.

Através da descrição, Flaubert projeta imagens sobre a "tela da representação verbal", sem relação causal alguma. A partir de um objeto que realiza uma ação durante a descrição, o narrador invadirá a memória do personagem, partilhará da mesma loucura sem nada explicar, e nós, leitores, entramos na mesma espécie de viagem frenética que ele descreve. A falta de cronologia e de explicação nessas cenas alucinantes é uma forma de escapar da linearidade e, portanto, de contestar a representação do real como uma tentativa de ilustração, de observação objetiva e de comprovação dos comportamentos dos personagens, tendência comum nos romances realistas.

Flaubert, através de sua linguagem, produz cenas repletas de coisas, de misturas de tempos verbais e cenas onde nada acontece no exterior:

(...) esse projeto de não dizer nada, essa recusa da expressão inaugura a experiência literária moderna. (...) O "livro sobre nada", o "livro sem sujeito", não foi escrito (e ninguém irá escrevê-lo), mas ele arremessou sobre todos os sujeitos, essa pesada espessura de linguagem petrificada que existia em abundância em seu gênio, essa esteira rolante, como disse Proust, de imperfeitos e de advérbios que podiam apenas reduzi-los ao silêncio. (GENETTE : 1966, p.242-3) ${ }^{10}$.

\section{Perec e as coisas que teriam existido}

\footnotetext{
${ }^{10}$ (...) ce projet de ne rien dire, ce refus de l'expression qui inaugure l'expérience littéraire moderne. (...) Le "livre sur rien ", le "livre sans sujet », il ne l'a pas écrit (et personne ne l'écrira), mais il a jeté sur tous les sujets dont foisonnait son génie cette lourde épaisseur de langage pétrifié, ce " trouttoir roulant ", comme dit Proust, d'imparfaits et d'adverbes qui pouvait seul les réduire au silence. " (tradução livre)
} 
O trabalho escritural inovador de Flaubert influenciou muitos escritores posteriores como Perec, que retoma explicitamente em sua obra algumas formas trabalhadas por Flaubert. A sensação de não-gratuidade da descrição, por exemplo, em Perec, sobretudo no romance que leva o título desafiador Les choses, é fortalecida por um livro que propõe apresentar "A história dos anos 60" através das coisas. A ideia de analisá-lo como um retrato dessa geração pode ser tentadora, mas se essa fosse a única interpretação possível, o romance já teria sido esquecido nas estantes empoeiradas de alguma biblioteca francesa e não causaria, até hoje, certo desconforto e desejo de prolongamento por parte de seus leitores.

O estranhamento começa a partir do primeiro capítulo de Les choses, que nos insere numa espécie de sonho, já que apresenta uma descrição irreal sem explicação alguma, em que o tempo verbal utilizado, o condicional presente, mistura as instâncias temporais. Como exemplo, poderíamos citar uma parte da descrição do primeiro quarto:

La première porte ouvrirait sur une chambre, au plancher recouvert d'une moquette claire. Un grand lit anglais en occuperait tout le fond. A droite, de chaque côté de la fenêtre, deux étagères étroites et hautes contiendraient quelques livres inlassablement repris, des albums, des jeux de cartes, des pots, des colliers, des pacotilles. (...) Au mur, au-dessus du lit préparé pour la nuit, entre deux petites lampes alsaciennes, l'étonnante photographie, noire et blanche, étroite et longue, d'un oiseau en plein ciel, surprendrait par sa perfection un peu formelle. ${ }^{11}$ (PEREC (1965): 2005, p. 11-2, grifo nosso)

Nesse trecho, encontramos diversos procedimentos nitidamente flaubertianos: a presença dos verbos de ação aplicados na descrição de objetos, como "abriria", "ocuparia", "conteria", a enumeração de diversos objetos ocupando o mesmo espaço do quarto, e a presença de objetos duplos, como "duas estantes", "entre duas pequenas lâmpadas", "dois criados-mudos de madeira e de cobre", "um par de navalhas inglesas", que marcaria a $o$ pensamento duplo burguês ${ }^{12}$, segundo Duchet (1969).

Quem viveria nesse espaço irreal, repleto de coisas descritas tão minuciosamente? Os personagens aparecerão em meio a esse mundo de objetos, como se representassem apenas mais um deles:

\footnotetext{
${ }^{11}$ « A primeira porta abriria para um quarto, de assoalho recoberto por um carpete claro. Uma grande cama inglesa ocuparia todo o fundo do ambiente. À direta, de cada lado da janela, duas estantes estreitas e altas conteriam alguns livros incansavelmente retomados, álbuns, jogos de cartas, potes, colares, miudezas. (...) $\mathrm{Na}$ parede, em cima da cama preparada para a noite, entre duas pequenas lâmpadas alsacianas, a atraente fotografia, em preto e branco, estreita e comprida, de um pássaro em pleno voo, surpreenderia por sua perfeição, um pouco formal." PEREC, G. As coisas - uma estória dos anos 60. Trad. T. C. Netto. SP : Nova Crítica, 1969, p.11-2.

12 “Pour les objets, il s'agit souvent, ici encore, d'une nécessité fonctionnelle : on voit mieux avec deux bougies; mais Flaubert met un soin irritant à signaler les objets doubles, qui reçoivent dès lors des connotations de bêtise lacinante, de monotonie itérative : " ... et elle restait accoudée sur le bord, entre deux pots de géranium ", " ...et elle restait le coude au bord de son assiette, entre les deux bougies qui brûlaient ", ou encontre de suffisance satisfaite, comme si le bourgeois pensait double.» DUCHET : 1969, p.28.
} 
Ils décachetteraient leur courrier, ils ouvriraient les journaux. Ils allumeraient une première cigarette. Ils sortiraient. Leur travail ne les retiendrait que quelques heures, le matin. Ils se retrouveraient pour déjeuner, d'un sandwich ou d'une grillade, selon leur humeur; ils prendraient un café à une terrasse, puis rentreraient chez eux, à pied, lentement ${ }^{13}$. (PEREC, idem, p. 15)

O pronome ils ("eles") também perturba a instância do personagem, pois não sabemos se estamos diante de um personagem determinado ou indeterminado. Ao contrário dos objetos, os personagens não serão descritos com tantos detalhes, não há nomes, características físicas, psicológicas ou diálogo para mostrar a relação entre os sujeitos. São destacadas apenas ações breves que aconteceriam todos os dias, repetidamente, que não apontam nenhum impacto ou mudança no cotidiano.

O início do segundo capítulo marca uma pausa da descrição perturbadora com uma frase quase explicativa: "Eles gostariam de ter sido ricos", ou seja, nenhum daqueles objetos citados anteriormente existiu e possivelmente não existirá, como sugere o tempo empregado (condicional passado).

Ils auraient aimé être riches. Ils croyaient qu'ils auraient su l'être. Ils auraient su s'habiller, regarder, sourire comme des gens riches. Ils auraient eu le tact, la discrétion nécessaires. Ils auraient oublié leur richesse, auraient su ne pas l'étaler. Ils ne s'en seraient pas glorifiés. Ils l'auraient respirée. Leurs plaisirs auraient été intenses. Ils auraient aimé marcher, flâner, choisir apprécier. Ils auraient aimé vivre. Leur vie aurait été un art de vivre. ${ }^{14}$ (PEREC, idem, p. 17)

A caracterização desse ils é construída de forma progressiva, como se fosse uma descrição narrada, porém, os verbos no condicional denunciam, logo de início, a busca degradada das personagens ${ }^{15}$ e a espécie de sonho acordado em que se encontram.

Emprestamos o termo "descrição narrada" de Nannicini (2004), que discute a presença da ekphrasis, conceito clássico para digressão narrativa, na escritura perequiana. Tratando da retomada desse conceito pela teoria literária moderna tanto como exercício estilístico e como precedente da própria descrição, a autora adota o termo para explicar "o caso que se limita à descrição verbal de um objeto, ou de uma obra de arte, sem que haja

\footnotetext{
13 "Abririam as cartas que chegassem, abririam os jornais. Acenderiam um primeiro cigarro, sairiam. $\mathrm{O}$ trabalho só os ocuparia por algumas horas, de manhã. Encontrariam-se para almoçar, um sanduíche ou um grelhado, conforme a disposição em que estivessem; tomariam café numa terraza, depois voltariam para casa, a pé, lentamente." PEREC, G. idem, p.14

14 “Eles gostariam de ter sido ricos. Acreditavam que teriam sabido sê-lo. Teriam sabido se vestir, olhar, sorrir como pessoas ricas. Teria tido o tato, a discrição necessária. Teriam esquecido sua riqueza, teriam sabido como não ostentá-la. Não se teriam glorificado com ela. Teriam-na respirado. Seus prazeres teriam sido intensos. Teriam gostado de caminhar, vadiar, escolher, apreciar. Teriam gostado de viver. Suas vidas teriam sido uma arte de viver." PEREC, G. idem, p.17.

${ }^{15}$ Segundo Luckács, em Teoria do romance, é essa busca fadada ao fracasso empreendida por personagens problemáticas que caracteriza o romance.
} 
um desencadeamento de história” ${ }^{16}$. Nannicini afirma que essa técnica narrativa é inovada em Perec, tanto que a divide em dois tipos presentes na obra do escritor: ekphrasis descritiva e ekphrasis descritiva e narrativa. A análise da autora, no entanto, revela alguns trechos em que essas duas frentes se entrecruzam e não conseguimos mais definir o que é só descritivo e o que é descritivo e narrativo.

Isso porque entendemos que a descrição narrada é semelhante a uma linguagem cinematográfica, mais especificamente, à construção de um roteiro. Como vimos nos últimos trechos de Les choses, as frases curtas, que se ligam umas às outras numa progressão atemporal, lembram pequenas cenas de um filme, ou um início de roteiro em que o cineasta listaria as características dos personagens a serem criados. A cena a seguir, de Jerôme, Sylvie e os amigos no Harry's New York Bar, ilustra bem o que entendemos como a linguagem cinematográfica em Perec:

Leur plus grand plaisir était d'oublier ensemble, c'est-à-dire, de se distraire. Ils adoraient boire, d'abord, et ils buvaient beaucoup, souvent, ensemble. Ils fréquentaient le Harry's New York Bar, rue Daunou, les cafés du PalaisRoyal, le Balzar, Lipp, et quelques autres. Ils aimaient la bière de Munich, la Guiness, le gin, les punchs bouillants ou glacés, les alcools de fruits. Ils consacraient parfois des soirées entières à boire, resserrés autour de deux tables rapprochées pour la circonstance, et ils parlaient, interminablement, de la vie qu'ils auraient aimé mener, des livres qu'ils écriraient un jour, des travaux qu'ils aimeraient entreprendre, des filmes qu'ils avaient vus ou qu'ils allaient voir, de l'avenir de l'humanité, de la situation politique, de leurs vacances prochaines, de leurs vacances passées, d'une sortie à la campagne, d'un petit voyage à Bruges, à Anvers ou à Bâle. Et parfois, se plongeant de plus en plus dans ces rêves collectifs, sans chercher à s'en éveiller, mais les relançant sans cesse avec une complicité tacite, ils finissaient par perdre tout contact avec la réalité. Alors, de temps en temps, une main simplement émergeait du groupe : le garçon arrivait, emportait les grès vides et en rapportait d'autres et bientôt la conversation, s'épaississant de plus en plus, ne roulait plus que sur ce qu'ils venaient de boire, sur leur ivresse, sur leur soif, sur leur bonheur. ${ }^{17}$ (PEREC, idem, p. 54-5, grifo nosso)

\footnotetext{
${ }^{16}$ « Nous pourrions ainsi définir comme ekphrasis descriptive le cas qui se limite à la description verbale d'un objet, ou d'une oeuvre d'art, sans qu'il y ait un déclenchement d'histoire. » (tradução livre)

17 “O maior prazer que tinham era esquecer em conjunto, isto é, distrair-se. Em primeiro lugar, adoravam beber, e bebiam muito, muitas vezes, juntos. Frequentavam o Harry's New York Bar, rua Daunou, os cafés do Palais-Royal, o Balzar, Lipp e alguns outros. Gostavam da cerveja de Munich, da Guiness, de gim, dos ponches ferventes ou gelados, dos licores de fruta. Destinavam às vezes tardes inteiras para beber, apertados ao redor de duas mesas postas juntas para a circunstância, e falavam, interminavelmente, da vida que gostariam de levar, dos livros que um dia escreveriam, dos trabalhos que gostariam de fazer, dos filmes que tinham visto ou que iam ver, do futuro da humanidade, da situação política, de suas próximas férias, de suas férias passadas, de uma viagem ao interior, de uma pequena viagem a Bruges, a Anvers ou a Bâle. E à vezes, mergulhando cada vez mais nesses sonhos coletivos, sem procurar despertar mas sim retomando-os incessantemente com uma cumplicidade tácita, acabavam por perder todo contato com a realidade. Assim, de vez em quando, uma mão simplesmente emergia do grupo: o garçom chegava, levava os copos vazios, trazia outros cheios e logo a conversa, tornando-se cada vez mais pastosa, desenrolava-se apenas sobre o que acabavam de beber, sobre a embriaguez em que estavam, sobre a sede que sentiam, sobre a felicidade deles." PEREC, G. idem, p.46-7.
} 
O narrador nos permite saber o bar que eles frequentam, as bebidas de que gostavam e o que faziam nas noitadas, no entanto, a precisão dos detalhes é deixada de lado quando eles conversam. Não temos acesso aos diálogos entre as personagens, e sim apenas a alguns dados contados pelo narrador. A cena começa com uma intensa descrição de detalhes marcados por termos definidos - como le Harry's New York Bar, les cafés, le Balzar, la bière, le gin - que vão sumindo paulatinamente para dar lugar à indeterminação des livres, des travaux, des films, d'une sortie e d'un petit Voyage à Bruges, à Anvers ou à Bale. Como se entrássemos (junto com as personagens) numa espécie de transe narrativo, vemos uma mão que emergia na cena, metonímia do garçom que os personagens pareciam não ver.

Observamos anteriormente, nos dois últimos exemplos de L'Éducation, como o narrador constrói a lembrança de Mme Arnoux a partir de um objeto (um jardim, uma palmeira, uma carta), e, nos trechos de Les choses, como a construção das imagens está baseada no desejo de riqueza do casal de forma que os próprios personagens se misturam às coisas, como se fossem, eles mesmos, descritos. No caso de Flaubert, o narrador onisciente se confunde com as palavras e os pensamentos de Frédéric e a linguagem é trabalhada de tal forma nessas passagens que nós (leitores) temos a sensação de que as imagens estão superpostas.

Procuraremos estabelecer a diferença entre a técnica flaubertiana e a perecquiana, por meio da análise de um trecho de L'Éducation... que fora re-escrito em Les choses. Tratase do momento em que Jérôme e Sylvie imaginam receber uma carta com a notícia de que herdavam uma grande fortuna de um tio distante. A reação do casal é semelhante a de Frédéric:

Ainsi rêvaient-ils, les imbéciles heureux: d'héritages, de gros lot, de tiercé. La banque de Monte-Carlo sautait; dans un wagon désert, une sacoche oubliée dans un filet; des liasses de gros billets; dans une douzaine d'huîtres, un collier de perles. Ou bien, une paire de fauteuils Boulle chez un paysan illettré du Poitou.

De grands élans les emportaient. Parfois, pendant des heures entières, pendant des journées, une envie frénétique d'être riches, tout de suite, imensément, à jamais, s'emparait d'eux, ne les lâchait plus.(...) Ils se livraient sans retenue aux délires de l'imaginaire. Partout où ils allaient, ils n'étaient plus attentifs qu'à l'argent. Ils avaient des cauchemars de millions de joyaux. ${ }^{18}$ (PEREC, idem, p. 101, grifo nosso)

Assim como o narrador flaubertiano anunciou o princípio da alucinação de Frédéric ("Com a clareza de uma alucinação"), o narrador perecquiano nos avisa que as imagens seguintes compõem os sonhos do casal. No entanto, há uma diferença na composição das imagens. No caso de Flaubert, a alucinação parte do objeto, mas não se restringe a ele, o narrador cria breves histórias em torno da lembrança de Mme Arnoux. A descrição cede espaço a uma narrativa alucinatória em torno do desejo por aquela mulher. No entanto, a alucinação do casal de Les choses é composta por múltiplas cenas potenciais, apenas

18 "Assim sonhavam eles, os imbecis felizes: com heranças, com a sorte grande, com apostas felizes. A banca Monte-Carlo quebrava; num vagão deserto, uma sacola esquecida num vão: maços de notas altas; numa dezena de ostras, um colar de pérolas. Ou então, um par de poltronas Boulle na casa de um camponês inculto do Poitou." PEREC, G. idem, p.84 
descritas, muitas vezes sem verbo, como vimos no último trecho citado, criando vazios que o leitor deverá preencher. Poderíamos ousar dizer que Les choses é uma possível realização de um livro (ou roteiro de filme?) sem sujeito, pois cria personagens paralisados por seu desejo e rodeados de coisas quase vivas, apesar de imaginadas. A força das Coisas não está em sua materialidade, mas na idéia fixa de poder, de controle, que manipula toda possibilidade de ação das personagens.

As imagens apresentadas são, mais uma vez, como descrições narradas: heranças, aposta de cavalos, roubo a banco, sacola com dinheiro esquecida num vagão, um colar de pérolas, um par de sofás caros na casa de um caipira analfabeto. Essas imagens sem ligação causal progridem e só fazem sentido no contexto do desejo de riqueza em que está inserido o casal de Les choses, nos pesadelos de milhões de jóias.

A força das Coisas não está em sua materialidade, mas na idéia fixa de poder, de controle, que manipula toda possibilidade de ação das personagens:

Le provisoire, le statu quo régnaient en maîtres absolus. Ils n'attendaient plus qu'un miracle. Ils auraient fait venir les architectes, les entrepreneurs, les maçons, les plombiers, les tapissiers, les peintres. Ils seraient partis en croisière et auraient trouvé, à leu retour, un appartement transformé, aménagé, remus à neuf, un appartement modèle, merveilleusement agrandi, plein de détails à sa mesure, des cloisons amovibles, des portes coulissantes, un moyen de chauffage efficace et discret, une installation électrique invisible, un mobilier de bon aloi.

Mais entre ces rêveries trop grandes, auxquelles ils s'abandonnaient avec une complaisance étrange, et la nullité de leurs actions réelles, nul projet rationnel, qui aurait consillé les nécessités objectives et leurs possibilités financières, ne venait s'insérer. $L^{\prime}$ immensité de leurs désirs les paralysait ${ }^{19}$. (PEREC, idem, p. 22-3, grifo nosso)

Vimos, ao longo da análise, a forma como Flaubert constrói a alucinação a partir dos objetos, forma que é re-apropriada por Perec em seu Les choses. Não se trata, porém, de mostrar simples identificações ou citações pontuais para atestar uma "filiação" de Perec a Flaubert e sim de discutir como ambos trabalharam certos procedimentos literários que abalam os limites entre o narrado e o descrito, entre os personagens e os objetos, entre a escritura e a re-escritura, enfim, entre a escritura literária e a escritura crítica.

\footnotetext{
19 “O provisório e o status quo imperavam como senhores absolutos. A única coisa que esperavam era um milagre. Teriam mandado vir os arquitetos, os empreiteiros, os pedreiros, os encanadores, os tapeceiros, os pintores. Partiriam num cruzeiro e quando voltassem encontrariam um apartamento transformado, arrumado, renovado, um apartamento modelo, maravilhosamente ampliado, cheio de detalhes apropriados, tabiques removíveis, portas corrediças, um meio de aquecimento eficaz e discreto, uma instalação elétrica invisível, um mobília de qualidade.

Mas entre esses sonhos demasiado grandes, aos quais eles se abandonavam com uma estranha complacência, e a nulidade de suas ações reais, nenhum projeto racional, que teria conciliado as necessidades objetivas e suas possibilidades financeiras, vinha inserir-se. A imensidão de seus desejos os paralisava." PEREC, G. idem, p.20-1.
} 
A re-escritura não é um fenômeno exclusivo da obra perecquiana. Segundo Gignoux (2003), "nós a encontramos em toda a literatura, e principalmente na modernidade, desde Joyce até Borges" ${ }^{20}$, e ela pressupõe a leitura do escritor e o desejo de voltar a escrever. Tanto em Perec quanto em Flaubert, o trabalho com a escrita que cria uma alucinação nos permitiu questionar a função dos objetos nas descrições, recusando a tendência de tomá-los como meros acessórios, e sim colocando-os como agentes participantes da narração.

Ao escrever suas obras, Perec busca uma linguagem própria a partir do desejo suscitado por suas leituras anteriores. Não é à toa que ele sempre afirmava seguir (leia-se citar) alguns "modelos", geralmente, do cânone literário como eram os "modelos" dos oulipianos quando decidiram recriá-los por meio de procedimentos matemáticos ou de restrições.

Contudo, o trabalho de Perec em seus textos não se reduz à colagens de citações pontuais ao acaso, trata-se de um trabalho refletido sobre o ato de escrever e sobre a própria literatura. É a partir desse procedimento que ele aponta para sua leitura de seus modelos, re-escrevendo e re-significando as formas já trabalhadas anteriormente. Dessa forma, Perec começa a nos revelar seu modo de pensar uma literatura possível no contexto de sua produção, e a forma que encontrou para traduzir em palavras questões não só da sociedade em que viveu, mas das possibilidades da escrita literária depois das inovações flaubertianas. $\mathbf{s}^{\mathbf{d}}$

\section{AGRADECIMENTOS}

A todos do grupo Criação e Crítica, especialmente, à Claudia, pela orientação e incentivo e à Samira, pelas leituras e indicações.

\section{REFERÊNCIAS BIBLIOGRÁFICAS}

DUCHET, C. (1969) “Roman et objets: I'exemple de Madame Bovary » in Travail de Flaubert.

GENETTE, G. ; TODOROV, T. (orgs). Paris : Seuil, 1983. pp.11-43.

FLAUBERT, Gustave (1869). L'Éducation sentimentale. Paris : Pocket Classiques, 1998. 519p.

GENETTE, G. Palimpsestes - La Littérature au Second Degré. Paris: Seuil, 1982. pp.1-20.

"Silences de Flaubert", Paris: Seuil, 1966. pp.223-43.

GIGNOUX, Anne-Claire. La récriture - formes, enjeux, valeurs. Autour du Nouveau Roman. Paris: Presses de l'Université de Paris Sorbonne, 2003. 198p.

20 “On la rencontre dans toute La littérature, et notamment dans la modernité, depuis Joyce jusque Borgès (...) »p. 8 
JORGE, Verónica Galindez. "Como as mil peças de um jogo de escritura nos manuscritos de Flaubert", tese de doutorado, USP: São Paulo, 2003.

NANNICINI, Chiara. "Perec et le renouveau de l'Ekphrasis ". in Le cabinet d'amateur - Revue d'études perequiens. MAGNÉ, B.; BERTELLI, D. (orgs.) Outubro 2004. Disponível no site http://www.cabinetperec.org/articles/nannicini-ekphrasis/nannicini-article.html. Acesso em: 2009

PEREC, Georges.(1965) Les Choses - une histoire des années soixante. Paris, Denoël, 2005. $157 \mathrm{p}$.

\section{Traduções:}

FLAUBERT, Gustave (1869). A educação sentimental. Tradução revista e adaptada pelo corpo editorial. São Paulo: W. M. Jackson Inc., Coleção Romances Universais, vol.18, 1963. 437p.

PEREC, Georges.(1965) As coisas - uma estória dos anos 60. Trad. T. C. Netto. SP : Nova Crítica, 1969. 135p.

PROUST, Marcel.(1920) “A propósito do 'estilo' de Flaubert”. In Nos caminhos da Crítica. São Paulo: Imaginário, 1994. pp.65-85.

Artigo recebido em: 30/07/09

Artigo aprovado em: 03/09/09

Referência eletrônica: MESSIAS, Carolina A. "O Pesadelo de um Milhão de Coisas - A escrita da alucinação em Flaubert e Perec", Revista Criação \& Crítica (online), n. 3, p.129-143,2009. 